\title{
Predator-prey interactions between two species of estuarine mysid shrimps
}

\author{
T. H. Wooldridge, P. Webb \\ Institute for Coastal Research and Department of Zoology, PO Box 1600, University of Port Elizabeth, Port Elizabeth 6000 , \\ South Africa
}

\begin{abstract}
Predatory feeding by the estuarine mysid Rhopalophthalmus terranatalis on Mesopodopsis slabberi was examined in laboratory experiments. Feeding rate increased linearly with increasing size of predator above $6 \mathrm{~mm}$ in body length. Smaller predators predated successfully on the copepod Pseudodiaptomus hessei. Predation rate was significantly correlated with prey size, with juvenile M. slabberi being most vulnerable. Predation rate was strongly related to prey density, suggesting a linear functional response. Large $R$. terranatalis showed a preferance for juvenile $M$. slabberi in choice experiments, even when the alternate species ( $P$. hessei) was present in high densities. Cannibalism was evident between aduit and small $R$. terranatalis. Estimates of predation rates on estuarine populations of $M$. slabberi indicate that $R$. terranatalis is potentially capable of eliminating recruitment into the $M$. slabberi population. However, differences in spatial distribution (vertical and horizontal), behaviour, and plasticity of the diet of $R$. terranatalis contribute to the co-existence of the 2 species in the Sundays estuary. Maximum predation would be encountered in the zone of overlapping distribution, with predation pressure by $R$. terranatalis decreasing progressively away from the boundary zone.
\end{abstract}

\section{INTRODUCTION}

Predation by mysid shrimps may have significant effects on composition and biomass of zooplankton communities. This has been well documented in cold limnetic waters, following the introduction of Mysis relicta as a food source for fish populations. Although regarded as an opportunistic omnivore (Grossnickle 1982), changes in zooplankton communities after the introduction of $M$. relicta were ascribed to predation by the mysid (Lasenby \& Langford 1973, Morgan et al. 1978, Goldman et al. 1979, Lynch 1979, Cooper \& Goldman 1980, Murtaugh 1981).

Omnivorous feeding of estuarine and marine mysids is also well documented (Tattersall \& Tattersall 1951, Mauchline 1980), but few studies have investigated the impact of mysid predation in these environments. In the Fraser river estuary (British Columbia, Canada), Neomysis mercedis predated heavily on meiobenthos, taking 12 to $13 \%$ of the harpacticoid population per day (Johnston \& Lasenby 1982). The potential impact of mysid predation on estuarine communities has also been shown for Mysidopsis bigelowi and Neomysis americana, species common in estuaries along the east coast of North America (Fulton 1982a, b). During winter in the Newport River estuary (North Carolina, USA), these 2 species of mysids were capable of consuming $25 \%$ of the daily standing crop of Acartia tonsa and $9 \%$ of the daily standing crop of Centropages spp. (Fulton 1982b). Although they feed omnivorously in the estuary, experimental data indicate that $M$. bigelowi and $N$. americana could significantly influence copepod abundance and species composition.

The mysids Rhopalophthalmus terranatalis and Mesopodopsis slabberi are abundant in the Sundays River estuary, southern Africa. Peak numbers occur in summer and population densities exceeding 4000 and 1200 mysids $\mathrm{m}^{-3}$ of water respectively have been recorded (Wooldridge \& Bailey 1982). Analysis of gut contents indicated that $M$. slabberi (particularly juveniles) formed a significant portion of the diet in $R$. terranatalis. Data were derived from 21 mo of extensive field sampling and it was suggested that predation by $R$. terranatalis played an important rôle in determining abundance and observed distribution patterns (Wooldridge \& Bailey 1982). A laboratory-based investigation was therefore initiated to quantify potential predatory feeding rates for different size class combinations of the 2 species. An attempt was then made to integrate experimental findings with field observations 
of abundance and behaviour of mysids and to determine whether predation could influence the distribution of $M$. slabberi in the estuary.

\section{MATERIALS AND METHODS}

Mysids for experimental purposes were collected in the Sundays River estuary, South Africa, by seine netting, immediately transferred into 201 sealed containers and transported to the laboratory.

Copepods required for prey preference experiments were collected at night using a conical plankton net of $124 \mu \mathrm{m}$ mesh aperture size. Collections contained a predominance of Pseudodiaptomus hessei, one of 2 species that together accounted for over $90 \%$ of the summer copepod biomass in local estuaries (Wooldridge \& Bailey 1982).

Experimental runs commenced around midday, within $2 \mathrm{~h}$ of collecting the predator species. Experimental temperature was set at $25^{\circ} \mathrm{C}$ and salinity maintained at $21 \%$. These reflect summer conditions in the estuary (Wooldridge \& Bailey 1982).

Predator densities used in experiments were representative of summer mysid concentrations. A constant number of 5 individuals in 2 l estuary water was used and this also ensured measurable rates of prey removal. Experimental prey density varied, depending on the objective. Experiments continued for $24 \mathrm{~h}$, with a 12L:12D photoperiod synchronized to ambient.

Experiments were done in glass beakers of $5 \mathrm{l}$ capacity. Fresh estuarine water was first filtered through a 124 um mesh sieve before being added to the beakers.

After completion of each experiment, live mysids were preserved, identified and counted. No differentiation was made between wholly or partly consumed specimens when determining the number of prey killed. Data sets in which moulting had occurred were excluded. A minimum of 6 replicates were completed for each experiment, but in most cases the number of replicates ranged between 8 and 10 .

Ontogenetic changes in feeding rates were investigated for 9 size classes of Rhopalophthalmus terranatalis $(4.0,5.0,6.0,6.7,8.3,10.0,11.7,13.3$ and $15.0 \mathrm{~mm}$ length; variation $\pm 0.5 \mathrm{~mm}$ ). These span the size range of summer-generation predators (Wooldridge 1986). An initial prey density of 10 Mesopodopsis slabberi per beaker, newly-released from the parent brood pouch (2.0 to $3.0 \mathrm{~mm}$ length), was used

Predation rate as a function of prey size was determined using Rhopalophthalmus terranatalis of $15.0 \pm$ $0.2 \mathrm{~mm}$ length. Predators were separated according to sex, while prey size classes ranged from newlyreleased young to a size when breeding commenced $(2.0,3.3,5.0,6.7,8.8,10.0$ and $10.8 \mathrm{~mm}$ length size classes; variation $<0.5 \mathrm{~mm}$ ). Twenty individuals were introduced into experimental containers in separate experiments for each size class. Nursery tanks were also set up to supplement the supply of prey, with brooding females bearing late-stage larvae replaced up to 4 times a week.

Predation rate as a function of prey density was determined over a range of 5 to 20 Mesopodopsis slabberi per beaker. Adult Rhopalophthalmus terranatalis $(15.0 \pm 0.2 \mathrm{~mm})$ were presented with 5,10 , 15 or 20 juvenile mysids ( 2.0 to $3.0 \mathrm{~mm}$ body length).

Prey preference experiments were done with adult Rhopalophthalmus terranatalis (15.0 $\pm 0.2 \mathrm{~mm})$, offering them 10 juvenile Mesopodopsis slabberi (2.0 to $3,0 \mathrm{~mm}$ ) and the copepod Pseudodiaptomus hessei at a density of 40 or 100 individuals per beaker. Copepod density corresponded to 20000 and $50000 \mathrm{~m}^{-3}$ in the estuary (Wooldridge \& Bailey 1982). Four control beakers excluded $M$. slabberi as prey.

Predation of juvenile Rhopalophthalmus terranatalis

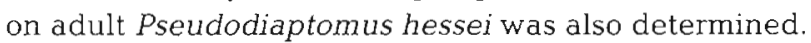
Three predator size classes were used $(4.0,6.0$ and 8.0 mm length; variation $\pm 0.2 \mathrm{~mm})$, the smallest representing individuals less than $48 \mathrm{~h}$ old (Wooldridge 1986). Twenty-five copepods were introduced into each experimental beaker.

Potential cannibalistic feeding was investigated between 3 size classes of Rhopalophthalmus terranatalis $\{10.0,12.0$ and $14.0 \mathrm{~mm}$ body length; variation $\pm 0.2 \mathrm{~mm}$ ), offering each group 10 juveniles of 4.0 , 6.0 and $8.0 \mathrm{~mm}$ ( $\pm 0.2 \mathrm{~mm}$ ) body length. Mixed juvenile assemblages of $10 R$. terranatalis and 10 Mesopodopsis slabberi were also offered to adult $R$. terranatalis. Prey were separated into $4.0 \mathrm{~mm}$ and $6.0 \mathrm{~mm}$ size classes.

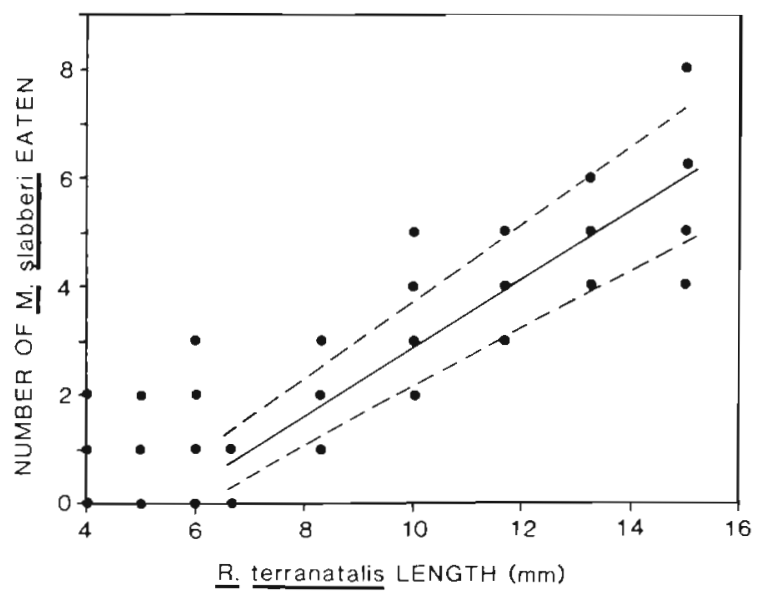

Fig. 1. Rhopalophthalmus terranatalis. Changes in predation rates (number of juvenile Mesopodopsis slabberi eaten by 5 mysids $d^{-1} \pm 95 \%$ confidence limits). This relation was only significant for predators larger than $6.0 \mathrm{~mm}$ body length 
Predation rates are expressed as the number of prey eaten per day by 5 Rhopalophthalmus terranatalis. Regression equations were fitted to data sets describing predation as a function of ontogenetic change, prey density and prey size. Predation of juvenile

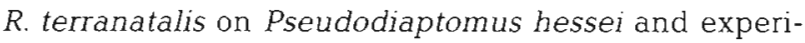
ments investigating cannibalism were treated in the same way. Differences between regressions were compared by Analysis of Covariance (Ancova). The pairedsample test was used to determine possible differences in predation on mixed replicates of juvenile $R$. terranatalis and Mesopodopsis slabberi. Comparison of adult male and female predation rates on different classes of prey size and prey choice experiments were compared using the Mann-Whitney Rank Sum Test.

\section{RESULTS}

\section{Laboratory experimentation}

Prey consumption rate (Fig. 1) increased linearly with increasing size of predators above $6.0 \mathrm{~mm}$ in body length ( $\mathrm{a}=-3.42, \mathrm{~b}=0.63 ; r=0.89, n=35$ ). Mysids of $6.0 \mathrm{~mm}$ or less in size were either non-predatory, or were not able to capture live Mesopodopsis slabberi and this is reflected in a lack of correlation between number of prey eaten and the body size of smaller predators $(r=0.36, n=53)$. When offered Pseudodiaptomus hessei as prey, these smaller Rhopalophthalmus terranatalis fed successfully on copepods (Fig. 2), suggesting their disability to capture mysids. The relationship between small $R$. terranatalis feeding on $P$. hessei was linear and expressed by $a=2.92, b=1.52 ; r=$ $0.70, n=29$.

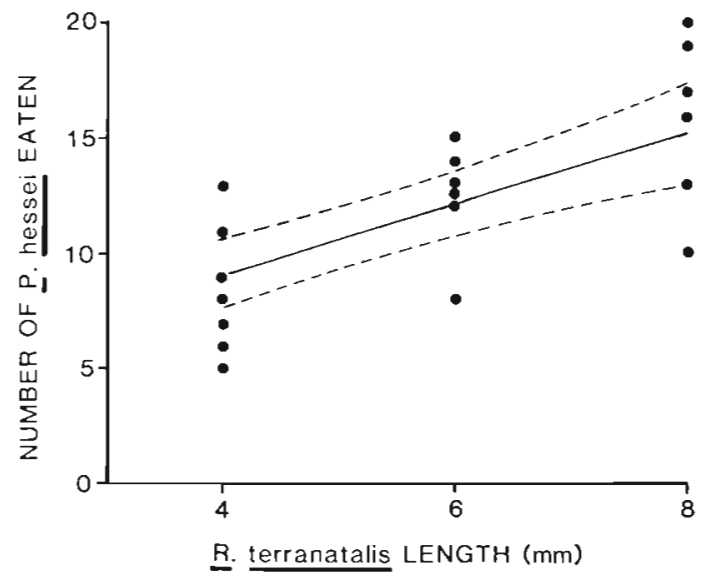

Fig. 2. Predation rates (number of prey eaten by 5 mysids $\mathrm{d}^{-1}$ ) of Rhopalophthalmus terranatalis of $4.0,6.0$ and $8.0 \mathrm{~mm}$ body length on adult Pseudodiaptomus hessei. Dashed lines represent $\pm 95 \%$ confidence limits

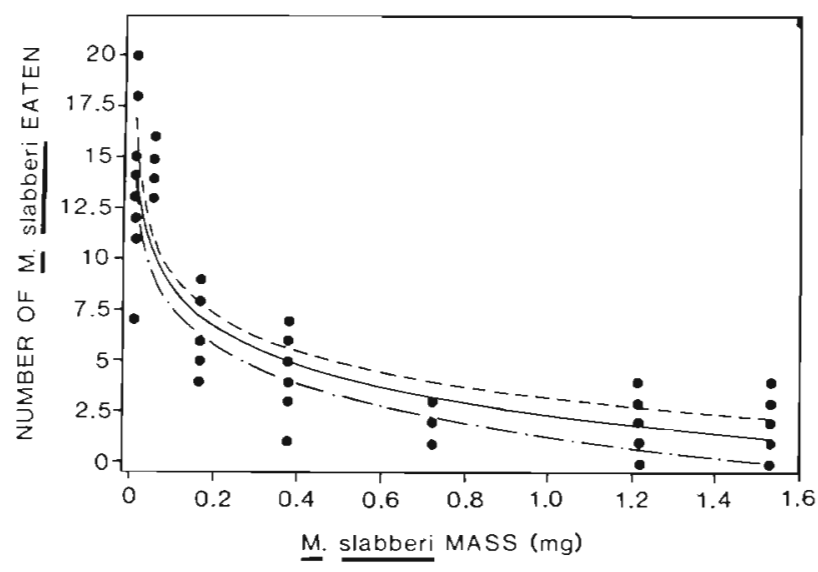

Fig. 3. Relation between prey mass (mg) and number consumed by 5 Rhopalophthalmus terranatalis $\mathrm{d}^{-1}$ Dashed lines represent $\pm 95 \%$ confidence limits

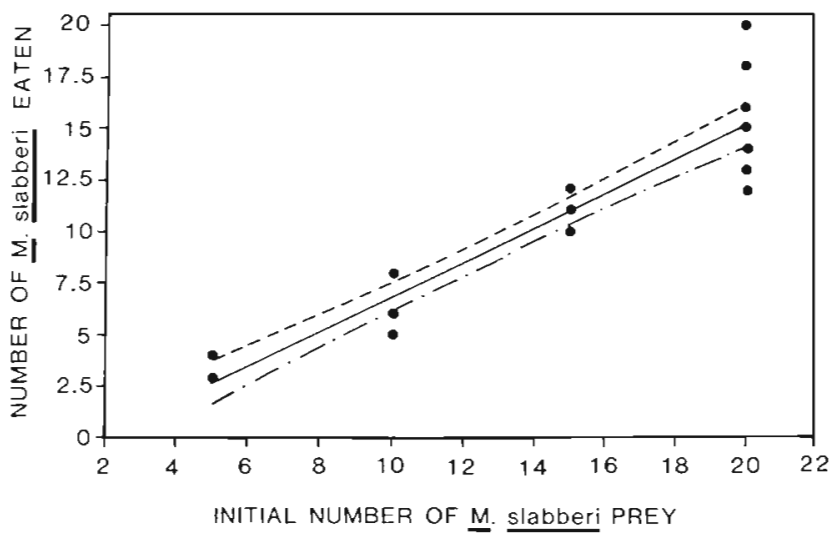

Fig. 4. Functional response of Rhopalophthalmus terranatalis (12 to $15 \mathrm{~mm}$ body length) feeding on 4 densities (numbers $2 \mathrm{l}^{-1}$ ) of juvenile Mesopodopsis slabberi. (Number of prey consumed by 5 mysids $\mathrm{d}^{-1} \pm 95 \%$ confidence limits.) $r=$ $0.95, n=29$

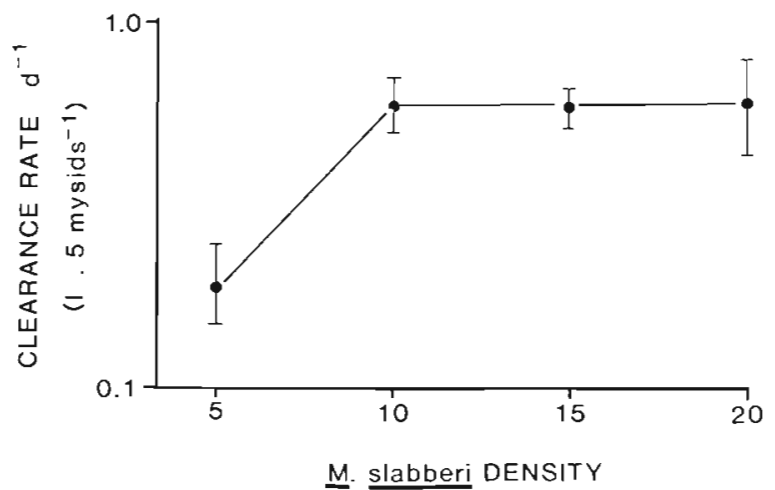

Fig. 5. Rhopalophthalmus terranatalis. Clearance rates (1 [5 mysids] $]^{-1} \mathrm{~d}^{-1}$ ) of adults as a function of initial prey density (number $2 \mathrm{l}^{-1}$ ). $95 \%$ confidence limits indicated 


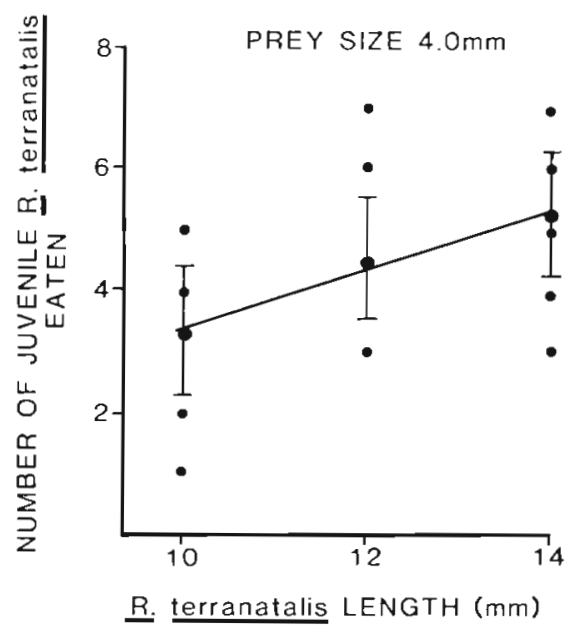

Fig. 6. Rhopalophthalmus terranatalis. Cannibalistic feeding by larger individuals $(10,12$ and $14.0 \mathrm{~mm}$ body length) on juveniles of $4.0 \mathrm{~mm}$ length (number eaten by 5 mysids $\mathrm{d}^{-1}$ ). Vertical bars represent $\pm 95 \%$ confidence limits
Predation was significantly correlated with prey mass (Fig. 3), with juveniles consumed in greater numbers compared to other size classes ( $r=0.87, n=56$ ). However, smaller individuals yielded a lower total mass than larger individuals ( $r=0.67, n=56)$. In some experiments however, no large prey were eaten (Fig. 3), suggesting that Rhopalophthalmus terranatalis had difficulty capturing them.

Male and female Rhopalophthalmus terranatalis of the same size did not differ significantly in the number of prey they consumed (Mann-Whitney Rank Sum Test, $p=1.000, n_{1}=28, n_{2}=28$. Mann-Whitney test statistic $=392$ )

Predation rates were strongly correlated with prey density (Fig. 4). At low densities (5 prey $21^{-1}$ ), numbers consumed were about one-fifth the number consumed at the highest densities offered (40 prey $\left.2 l^{-1}\right)$. When expressed in terms of the functional response, clearance rate per day remained constant at the 3 highest

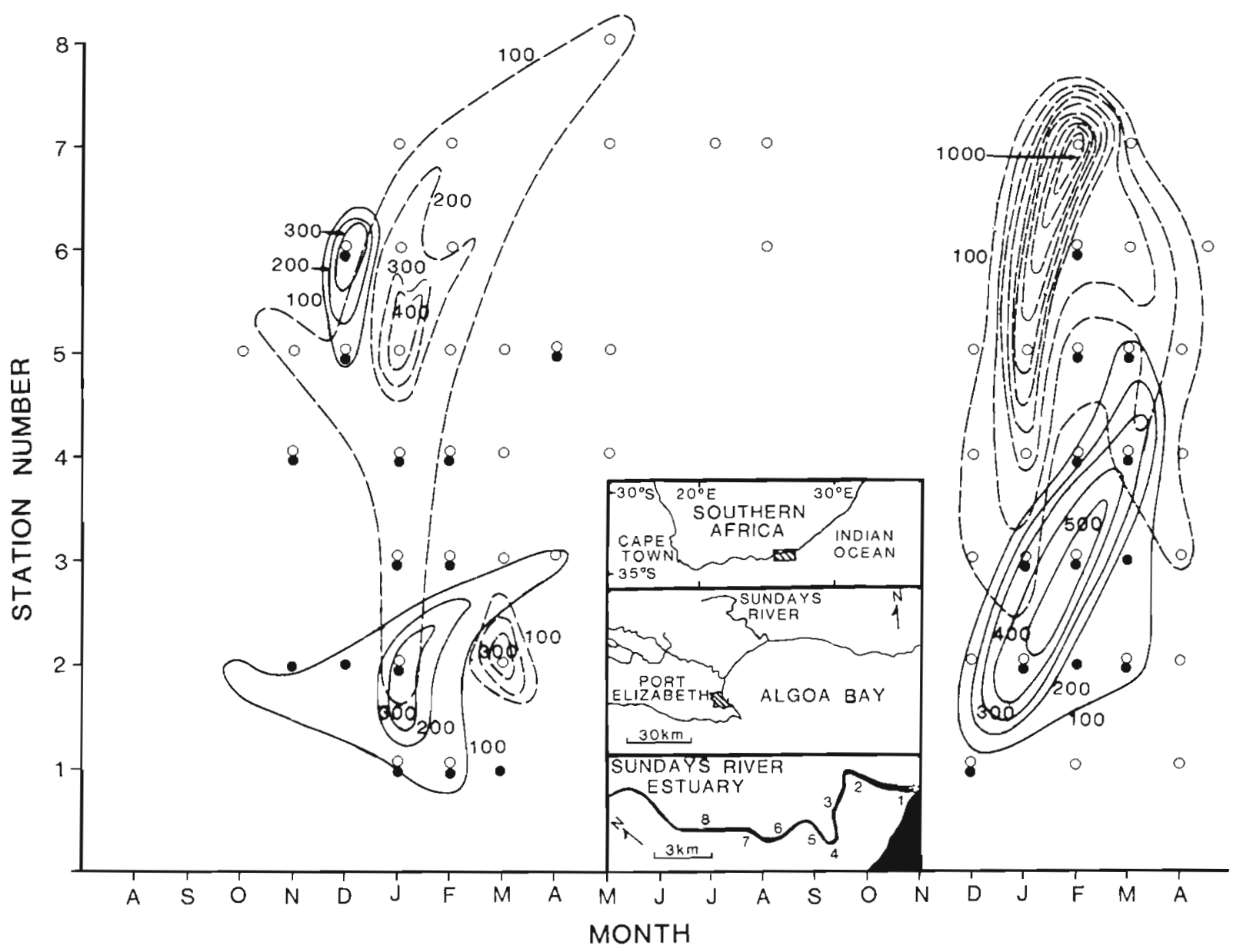

Fig. 7 Distribution (numbers $\mathrm{m}^{-3}$ ) of Rhopalophthalmus terranatalis ( $>12.0 \mathrm{~mm}$ body lengthi,---$)$ and adult Mesopodopsis slabberi $(\bullet,-)$ during a 21 mo study in the Sundays estuary (Wooldridge \& Bailey 1982). Inset depicts the geographical location and stations sampled in the estuary. Contours represent mysid gradients (interval 100 mysids $\mathrm{m}^{-3}$ ) with a minimum of 100 ind. $\mathrm{m}^{-3}$ 
prey densities (Fig. 5). At an initial prey density of 5 ind. $21^{-1}$, clearance rates were significantly lower.

The number of juvenile Mesopodopsis slabberi consumed did not differ significantly between experimental sets in which mysids were the only prey (data from Fig. 1) or when they were mixed with Pseudodiaptomus hessei. In mixed assemblages, less than $15 \%$ of copepods were eaten in any experiment Mann-Whitney Rank Sum Test, $p=0.4676, n_{1}=14, n_{2}=12$. Mann-Whitney test statistic $=70.50)$.

Cannibalism was evident between large and small Rhopalophthalmus terranatalis under experimental conditions. There was a significant linear correlation (Fig. 6) between predator size and predation rate for mysids of 10 to $14 \mathrm{~mm}$ body length feeding on $4.0 \mathrm{~mm}$ juveniles $(\mathrm{a}=-1.37, \mathrm{~b}=0.48 ; p<0.005, r=0.49, n=$ $30)$, but no correlation was evident when prey size exceeded $6.0 \mathrm{~mm}$. In prey choice experiments, the number of juvenile mysids of either species consumed in the $4.0 \mathrm{~mm}$ size class did not differ significantly $(t=$ $0.755, p>0.01$, df $=8$ ), whereas at a prey size of
$6.0 \mathrm{~mm}$, significantly higher numbers of Mesopodopsis slabberi were consumed compared to $R$. terranatalis $(t=5.500, p<0.001, \mathrm{df}=9)$. There was no difference in the total number of prey consumed in the 4.0 and $6.0 \mathrm{~mm}$ size classes $(t=0.744, p>0.01, \mathrm{df}=8)$, supporting the conclusion that there was a significant switch to non-cannibalistic feeding when potential prey reached about $6.0 \mathrm{~mm}$ in length.

\section{Field observations}

Spatial and temporal patterns of distribution (numbers $\mathrm{m}^{-3}$ of water) for the 2 species of mysid shrimps are detailed in Wooldridge \& Bailey (1982) and Wooldridge (1986). Data pertinent to the present study are presented in Figs. 7 and 8. Both Rhopalophthalmus terranatalis and Mesopodopsis slabberi attain maximum density in midsummer, with the predator species occurring higher up the estuary compared to $M$. slabberi. These data are representative for the water col-

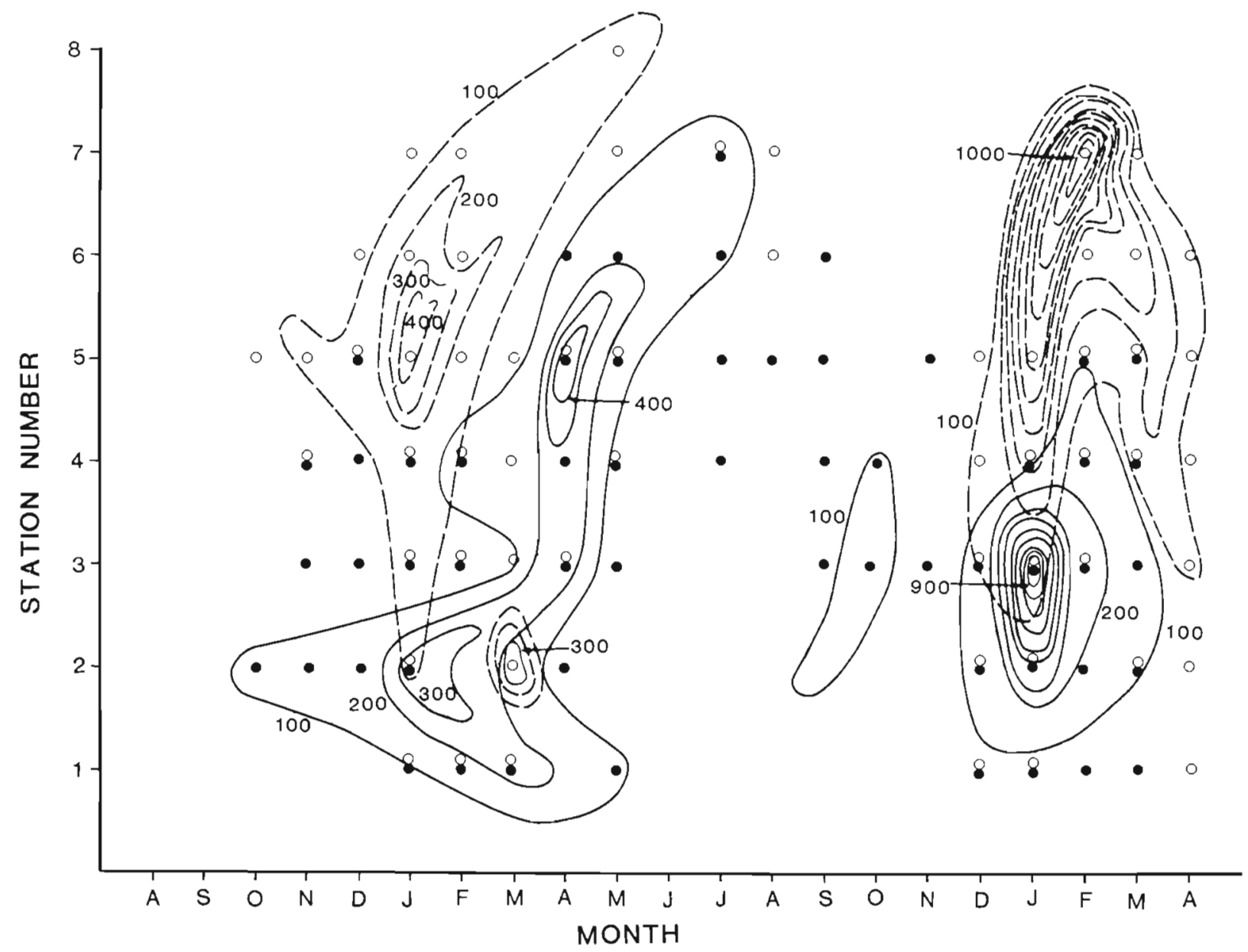

Fig. 8. Distribution (numbers $\mathrm{m}^{-3}$ ) of Rhopalophthalmus terranatalis ( $>12.0 \mathrm{~mm}$ body length; $0_{1}---$ ) and juvenile Mesopodopsis slabberi $(\bullet,-$ ) during a 21 mo study in the Sundays estuary (Wooldridge \& Bailey 1982). Further details as for Fig. 7 
Table 1. Rhopalophthalmus terranatalis $(>12 \mathrm{~mm}$ body length) and juvenile Mesopodopsis slabberi. Population densities (ind $\mathrm{m}^{-3}$ ) in mid-summer 1980 and 1981 for different regions in the Sundays estuary. Data are from Wooldridge \& Bailey (1982) and are the mean for the water column at stations indicated (see inset, Fig. 7)

\begin{tabular}{|c|c|c|c|c|c|c|}
\hline & \multicolumn{6}{|c|}{ Estuarine station } \\
\hline & 2 & 3 & 4 & 5 & 6 & 7 \\
\hline \multicolumn{7}{|l|}{ January 1980} \\
\hline R. terranatalis & 121 & 159 & 156 & 458 & 250 & 71 \\
\hline Juvenile $M$. slabberi & 362 & 87 & 64 & 13 & 9 & 5 \\
\hline \multicolumn{7}{|l|}{ January 1981} \\
\hline R. terranatalis & 73 & 103 & 384 & 581 & 6 & 0 \\
\hline Juvenile $M$. slabberi & 383 & 950 & 63 & 5 & 1 & 0 \\
\hline
\end{tabular}

umn (water depth generally $<5 \mathrm{~m}$ ), and are mean values from multilevel sampling. Specific population densities for adult predators and juvenile prey are given in Table 1 and represent summer peaks in abundance along the axis of the estuary.

\section{DISCUSSION}

Predation of adult Rhopalophthalmus terranatalis on juvenile Mesopodopsis slabberi increased linearly with increasing prey density over the range 2500 to 10000 prey $\mathrm{m}^{-3}$ of water. These investigations were carried out under a $12 \mathrm{hL}: 12 \mathrm{hD}$ photoperiod. Under the same conditions and using $1 \mathrm{l}$ beakers, a linear response was also recorded for Mysidopsis bigelowi (Fulton 1982b); but in the latter case, the fitted regression line reflected a positive $Y$-intercept. As pointed out by Fulton (1982b), the response must in some way be non-linear and when expressed in terms of clearance rate, a curvilinear functional response was apparent. In the present study a Y-intercept of zero was recorded (Fig. 4), while clearance rate (Fig. 5) was constant at the 3 highest values. These data suggest a linear functional response. However, at a prey density of only 5 ind. $2 \mathrm{l}^{-1}$, clearance rate was significantly lower (Fig. 5). In this case, a reduced encounter rate between live prey and predators may have been supplemented by greater utilization of dead prey, partly consumed and discarded by other individuals.

Although Rhopalophthalmus terranatalis are omnivorous (Wooldridge \& Bailey 1982) a greater proportion of the diet in adults consists of animal material than in juveniles. This follows the pattern described for other predatory feeding mysids (Lasenby \& Langford 1973, Cooper \& Goldman 1980, Siegfried \& Kopache 1980, Johnston \& Lasenby 1982). The flexibility of the feeding habits of $R$. terranatalis is well illustrated following riverine flooding of the Sundays estuary
(Wooldridge \& Bailey 1982). Mysids recolonized the estuary from adjacent coastal waters within a short time of the flushing event and prior to the re-establishment of other estuarine zooplankton populations, consumed detritus and other fragments of plant material, some of which was of terrestrial origin. As the estuarine zooplankton community became re-established, the diet reflected a progressive shift towords carnivory (Wooldridge \& Bailey 1982).

Large Rhopalophthalmus terranatalis also consume a greater number of mysid prey compared to juveniles. Individuals of less than $6.0 \mathrm{~mm}$ however, are not capable of capturing even the smallest live Mesopodopsis slabberi. Instead, they feed successfully on Pseudodiaptomus hessei. Adult $R$. terranatalis showed a preference for $M$. slabberi over copepods, even when $P$. hessei was present in high concentrations $\left(50000 \mathrm{~m}^{-3}\right)$. In natural assemblages, copepods co-exist in high abundance with $R$. terranatalis. During the summer of 1981, maximum numbers of $P$. hessei (excluding nauplii) exceeded $20000 \mathrm{~m}^{-3}$ in mid-estuarine regions where $R$. terranatalis was most abundant (Wooldridge 1986). Thus $R$. terranatalis newly released from the brood pouch have a copepod food source available to them which they are capable of exploiting. As they increase in size, there is a preference for larger prey such als $M$. slabberi, although gut analysis indicates that $P$. hessei and other copepods are also consumed (Wooldridge \& Bailey 1982).

An estimate of the potential impact of predatory feeding by Rhopalophthalmus terranatalis on Mesopodopsis slabberi is possible by integration of field and experimental data. Growth of summer generation $R$. terranatalis is rapid, attaining a body length of $6.0 \mathrm{~mm}$ in $15 \mathrm{~d}$ (Wooldridge 1986). During the remainder of their lifespan ( 6 to $7 \mathrm{mo}$ ), they predate successfully on $M$. slabberi, with largest predators having the greatest effect. Average body length of adult $R$. terranatalis ranges between 12 and $15 \mathrm{~mm}$ (Wooldridge 1986) and these larger predators are capable of consuming about 1 mysid predator ${ }^{-1} \mathrm{~d}^{-1}$ (Fig. 1).

Using empirical data for midsummer maxima (January 1980) for adult predators and juvenile prey (Table 1), Rhopalophthalmus terranatalis could potentially eliminate juvenile Mesopodopsis slabberi within $3 \mathrm{~d}$ in the region of maximum prey density (Station 2, Table 1). As predator density increased upstream, prey decreased in abundance and could be removed in a shorter time.

Similarly, in January 1981, prey could be potentially removed in ca $9 \mathrm{~d}$ at Station 3. As predator density increased, there would again be an inverse relation with daily removal rates of prey in an upstream direction.

These potential predation rates are greater than the 
rate of recruitment into the prey population. The production: biomass ratio for Rhopalophthalmus terranatalis is 7.85 (Wooldridge 1986), while unpublished observations indicate a similar value for Mesopodopsis slabberi. In the latter species, mean brood size in midsummer is about 14 embryos per female and these take about $10 \mathrm{~d}$ to develop before release by the parent. Given an average midsummer population density in 1980 of $220 R$. terranatalis $\mathrm{m}^{-3}$ of water (> $12.0 \mathrm{~mm}$ length; Wooldridge \& Bailey 1982), a prey density greater than 170 adult females $\mathrm{m}^{-3}$ is necessary to maintain the prey population in the estuary. Field data indicate that the average number of adult female $M$. slabberi in the estuary at this time was only 100 ind. $\mathrm{m}^{-3}$ (Wooldridge \& Bailey 1982). Similarly, in midsummer of the following year, average predator density was about 230 ind. $\mathrm{m}^{-3}$ while adult female $M$. slabberi averaged 105 $\mathrm{m}^{-3}$. Thus predation by $R$. terranatalis could potentially result in zero recruitment into the adult breeding population of $M$. slabberi.

Since Mesopodopsis slabberi survived through the summer in both years of study (Wooldridge \& Bailey 1982), various mechanisms must operate which reduce the impact of the predator on the prey species. Spatially, Rhopalophthalmus terranatalis is more abundant in mid-estuarine regions where salinity ranges between 15 and $25 \%$ (Woolridge \& Bailey 1982). $M$. slabberi is more abundant nearer the mouth, but an overlap zone occurs (Wooldridge \& Bailey 1982). Adult distribution patterns are illustrated in Fig. 7 which shows an up-estuary extension of the 2 populations towards the end of the first summer. This corresponded to a salinity increase throughout the estuary (Wooldridge \& Bailey 1982). Towards the end of the second summer, salinities decreased and there was a shift towards the estuary mouth. This would suggest that salinity, at least in part, played a rôle in establishing observed spatial distributions for the 2 species. Maximum densities of juverile $M$. slabberi mirrored that of the adult component, although juveniles showed a much more marked up-estuary movement at the end of the first summer (Fig. 8). In summary, predators and juvenile prey reflect adjacent spatial distribution patterns, but a zone of overlap does occur.

Lasenby \& Langford (1973) have suggested that Mysis relicta is more active at night as a predator, while Siegfried \& Kopache (1980) report a similar pattern for large Neomysis mercedis. In the latter species, carnivory accounted for $90 \%$ of the energy represented by food material present in the guts of these mysids. An increase in nocturnal predation is also evident for Gastrosaccus psammodytes along sandy shores in southern Africa (Webb pers. comm.). It is not known whether Rhopalophthalmus terranatalis exhibits diel changes in feeding habits, but all gut analyses which reflected a carnivorous diet were done on mysids collected at night (Wooldridge \& Bailey 1982). At this time spatial separation of different size classes of mysid populations is evident in the water column (Wooldridge \& Erasmus 1980 ). Adult $R$. terranatalis do not undergo a general migration info surface waters, but remain in bottom waters irrespective of the tide or light intensity (Wooldridge \& Erasmus 1980). This pattern of greater abundance of larger mysids near the bottom of the water column (Wooldridge \& Bailey 1982) was also consistant during multi-level sampling at all stations in the Sundays estuary (Chi Square Test, $p<0.01, n=66$ ), while juvenile Mesopodopsis slabberi occur near the surface in greater abundance compared to near-bottom waters (Chi Square Test, $p<0.01, n=66$ ). Spatial vertical separation of the predator from the most vulnerable fraction of the prey species is therefore evident in the water column at night. This, coupled with separate peaks in population densities along the axis of the estuary, would result in reduced predator-prey encounters.

The present study suggests that Rhopalophthalmus terranatalis is capable of eliminating recruitment stock into the Mesopodopsis slabberi breeding population. $R$. terranatalis attains higher population densities and both species of mysids have similar population turnover rates. Predation is suggested as the major factor in maintaining the relatively sharp boundary between the 2 populations, but horizontal and vertical preferences in spatial distribution, behavioural patterns and the plasticity of the diet in $R$. terranatalis ensures the $\mathrm{CO}$ existance of the 2 species in the estuary. Maximum predation by $R$. terranatalis would be encountered in the zone of overlap, with predation pressure on $M$. slabberi decreasing progressively away from the boundary zone.

Acknowledgements. Financial support was provided through the CSIR and Department of Environmental Affairs, South Africa. The assistance of L. D. van Essen is also gratefully acknowledged.

\section{LITERATURE CITED}

Cooper, S. D., Goldman, C. R. (1980). Oppossum shrimp (Mysid relicta) predation on zooplankton. Can. J. Fish. Aquat. Sci. 37: 909-919

Fulton, R. S., III (1982a). Preliminary results of an experimental study of the effects of mysid predation on estuarine zooplankton community structure. Hydrobiologia 93: $79-84$

Fulton, R. S., III (1982b). Predatory feeding of two marine mysids. Mar. Biol. 72: 183-191

Goldman, C. R., Morgan, M. D., Threlkeld, S. T., Angeli, N (1979). A population dynamics analysis of the cladoceran disappearance from Lake Tahoe, California/Nevada. Limnol. Oceanogr. 24: 289-297 
Grossnickle, N. E. (1982). Feeding habits of Mysis relicta an overview. Hydrobiologia 93: 101-107

Johnston, N. T., Lasenby, D. C. (1982). Diet and feeding of Neomysis mercedis Holmes (Crustacea, Mysidacea) from the Fraser River estuary, British Columbia. Can. J. Zool. 60: $813-824$

Lasenby, D. C., Langford, R. R. (1973). Feeding and assimilation of Mysis relicta. Limnol. Oceanogr. 18: 280-285

Lynch, M. (1979). Predation, competition and zooplankton community structure: an experimental study. Limnol. Oceanogr. 24: 253-272

Mauchtine, J. (1980). The biology of mysids and euphausiids. In: Blaxter, J. H. S., Russel, F. S., Younge, M. (eds.) Advances in marine biology, Vol. 18. Academic Press, New York, p. 1-369

Morgan, M. A., Threlkeld, S. T., Goldmann, C. R. (1978). Impact of the introduction of kokanee (Oncorhynchus nerka) and opossum shrimp (Mysis relicta) on a subalpine lake. J. Fish. Res. Bd Can. 35: 1572-1579
Murtaugh, P. A. (1981). Selective predation by Neomysis mercedis in Lake Washington. Limnol. Oceanogr. 26: $445-453$

Siegfried, C. A., Kopache, M. E. (1980). Feeding of Neomysis mercedis (Holmes). Biol. Bull. mar. biol. Lab., Woods Hole 159: 193-205

Tattersall, W. M., Tattersall, O. S. (1951). The British Mysidacea. Ray Society Monograph, London

Wooldridge, T (1986). Distribution, population dynamics and estimates of production for the estuarine mysid. Rhopalophthalmus terranatalis. Estuar. coast. Shelf Sci. 23: 205-223

Wooldridge, T., Bailey, C. (1982). Euryhaline zooplankton of the Sundays estuary and notes on trophic relationships. S. Afr. J. Zool. 17: 151-163

Wooldridge, T., Erasmus, T (1980). Utilization of tidal currents by estuarine zooplankton. Estuar, coast. mar. Sci. 11. $107-114$

This article was submitted to the editor; it was accepted for printing on September 7,1988 